\title{
O parto em contexto Narrativas da gravidez entre gestantes no Rio de Janeiro
}

\author{
Birth in the context \\ Narratives of pregnancy in Rio de Janeiro
}

Claudia Barcellos Rezende*

\begin{abstract}
Resumo: Neste trabalho, busco refletir sobre a centralidade do parto como projeto, presente em certos grupos de gestante e mesmo em políticas de humanização do parto. A partir de entrevistas com mulheres de camadas médias do Rio de Janeiro que esperavam seus primeiros filhos, discuto como este material constitui-se em uma narrativa, com começo (o desejo de ter filhos e a concepção), meio (a mudança nos comportamentos e na relação com outros) e fim (o parto antecipado). Examino quais elementos e fios condutores se destacam, quais atores sociais são incorporados nestas histórias e de que modo. Argumento que a gravidez pode ser vista como uma categoria cultural que informa a experiência física e subjetiva da gestação, articulada a noções de pessoa e gênero. $\mathrm{O}$ material analisado sugere que a gravidez como um todo, incluindo o parto, se torna um projeto para as mulheres pesquisadas, tensionado entre noções de feminilidade e de maternidade.
\end{abstract}

Palavras-chave: Gravidez. Parto. Camadas médias.

\begin{abstract}
In this article, I intend to discuss the centrality of birth as a personal project, which appears among some pregnancy support groups and public policies for the humanization of births. Based on interviews with middle class pregnant women in Rio de Janeiro, who expected their first child, I discuss how this material takes on the form of narratives with a beginning (the desire to have a child which lead to conception), its development (the actual experience of gestation) and an end (the anticipated birth). I examine the elements and social actors which are significant in these stories, bearing in mind that pregnancy is a cultural category that informs the physical and subjective experience of gestation. The material analysed suggests that pregnancy as a whole, including birth in the end, becomes a project carefully planned by the women researched, based on conflicting notions of femininity and motherhood.
\end{abstract}

Keywords: Pregnancy. Birth. Middle classes.

\footnotetext{
* Doutora em Antropologia pela London School of Economics and Political Sciences (LSE, Londres, Inglaterra), professora associada da Universidade do Estado do Rio de Janeiro (Uerj) no Rio de Janeiro, RJ, Brasil<cbrezende@bighost.com.br>. Uma versão anterior deste trabalho foi apresentada na 29ํㅡㄹ Reunião Brasileira de Antropologia (Natal, RN, 3-6 ago. 2014). Agradeço aos comentários das debatedoras Fernanda Bittencourt Ribeiro e Rosamaria Giatti Carneiro. Os dados analisados aqui resultam da pesquisa Pertencimento e parentesco na gravidez, apoiada pelo Programa Prociência da Uerj, pelo CNPq(Bolsa de Produtividade) e pela Capes (Bolsa Estágio Sênior). Priscilla Silva, Thales Moraes e Bruno Hammes participaram como assistentes de pesquisa.
}

Civitas, Porto Alegre, v. 15 , n. 2, p. 214-228, abr.-jun. 2015 
Nos últimos anos, o tema do parto tem recebido crescente atenção nas ciências sociais brasileiras. Em muito, isto se deve à discussão sobre humanização no parto, ${ }^{1}$ com sua proposta de modelos alternativos ao atendimento médico hospitalar, com uma série de procedimentos médicos questionados a partir de uma busca por formas mais "naturais" de parir. Neste debate, o parto aparece também como "forma de empoderamento das mulheres" (Tornquist, 2002, p. 483), assumindo uma centralidade na vivência física e subjetiva de gestar um bebê, ficando de lado os meses de gravidez que o antecedem e mesmo a expectativa do que vem depois. Ao mesmo tempo, esta importância coexiste com mudanças geradas a partir de novas tecnologias reprodutivas, que deram aos aspectos biológicos da maternidade novos sentidos. Em particular, destaco as práticas de aluguel de útero que retiram do parto sua associação necessária com a maternidade (Ragoné, 1997; Thompson, 2001).

Por outro lado, em minha pesquisa de campo com gestantes no Rio de Janeiro, o parto recebeu atenção variada. Ao longo dos meses em que acompanhei um grupo de gestante na zona sul da cidade, este era um dos temas de discussão preferidos. Mais do que falar do presente, as mulheres discutiam suas sensações e expectativas sobre um evento futuro, assistindo vídeos e fazendo dramatizações detalhadas. Já nas entrevistas realizadas em uma etapa posterior da pesquisa, o parto dividia atenção com o momento inicial da confirmação da gestação, bem como com a experiência presente. Dificilmente surgia espontaneamente e era bem menos elaborado do que no contexto do grupo de gestante, cujo objetivo principal era de fato preparar a gestante para o parto e o pós-parto.

A partir deste material, gostaria de refletir, neste artigo, sobre o lugar do parto na experiência da gravidez. Os depoimentos sobre a gravidez que analiso trazem uma estrutura narrativa, com começo, meio e fim, no caso antecipado. Enquanto forma discursiva, a narrativa está sujeita a procedimentos de composição referidos à temporalidade - ao passado, presente e futuro (Arfuch, 2010, p. 111). A narrativa se coloca como forma de estruturação da experiência, na medida em que cria uma relação entre o tempo do mundo da vida e o tempo do relato. Estas narrativas são informadas pela gravidez enquanto uma categoria cultural que informa uma experiência física e subjetiva, por sua vez pautada por certas construções de pessoa, gênero e de maternidade (Ivry, 2010). Assim, como sugerem Thomson et al. (2011, p. 14), ao narrarem suas gestações, as mulheres falam de si para outros através de histórias que

\footnotetext{
${ }^{1}$ Ver, dentre outros, os estudos de Carneiro (2012), Diniz (2005), Hirsch (2014), Mendonça (2013) e Tornquist (2002).
} 
articulam suas biografias pessoais a mudanças nas relações sociais. O parto figura, portanto, como o ponto final de uma narrativa na qual o planejamento é um dos fios condutores.

Minha pesquisa se baseia em duas fontes de dados: um período de observação participante em um grupo de gestantes na zona sul do Rio de Janeiro e um conjunto de entrevistas realizadas com mulheres de camadas médias que esperavam seu primeiro filho. Em ambas as situações de campo, as mulheres tinham idades entre 28 e 35 anos e estavam em relações heterossexuais estáveis. Todas trabalhavam em ocupações de classe média e tinham educação universitária (embora metade delas tivesse pais com escolaridade inferior). Praticamente todas possuíam o imóvel no qual residiam, que sofria reforma para a chegada do bebê. Metade das mulheres morava em bairros da zona norte e do subúrbio do Rio de Janeiro, mais heterogêneos em termos socioeconômicos, enquanto as outras viviam em bairros da zona sul, mais homogêneos e de camadas médias. Havia entre elas uma diversidade de pertencimentos religiosos - religiões afro-brasileiras, pentecostais, messiânica, judeus e católicos, com graus variados de adesão e de prática.

Os maridos e companheiros eram descritos como muito entusiasmados e participantes da gestação, buscando se informar, assistindo às ultrassonografias e acompanhando quando possível às consultas médicas. Todas tinham convênio particular de saúde. A maioria tinha mudado de ginecologista após a confirmação da gravidez, buscando um obstetra que fosse pago pelo plano de saúde, e em muitos casos, a relação recente com o médico gerava ansiedade. Todas as mulheres relatavam ter relações próximas com suas famílias que em geral moravam perto de suas filhas e participavam intensamente da gestação. A relação com os sogros também era de bastante convivência, mas apresentava mais tensões. Aprofundo a análise destas relações em outro trabalho (Rezende, 2011a), mas neste momento apresento-as como a rede de relações mais imediatas na qual a gestante estava inserida.

\section{A concepção}

Lucimar estava casada há oito anos quando engravidou. Evangélica e trabalhando como enfermeira, planejou a gravidez para quando tivesse terminado seus estudos, ainda que seu marido, Daniel, achasse que eles pudessem esperar mais um pouco. Conta ela: "Como eu sou mulher e a mulher sempre acaba decidindo isso, é claro, quando tem um bom marido [...]. Então eu mesma me programei... Ai me preparei, fui procurar estudar sobre meu dia fértil, e... mantive relação naquele dia, já sabia que eu ia ficar grávida [...] primeiro porque eu pedia muito um filho a Deus e eu sabia que a hora que 
realmente eu pedisse, Deus ia me conceder um filho.... E segundo eu optei também pela ciência, juntou os dois, Deus em primeiro lugar e depois a ciência! Ai eu engravidei”. Daniel ficou surpreso de início, mas depois ficou muito feliz, buscando ler tudo sobre gestação. Já no final da gravidez, na época da entrevista, Lucimar estava se sentindo cansada e inchada. Mas, diz ela, "tirando esses contratempos, pra mim é ótimo, porque foi uma coisa que eu planejei, senti a vontade e assim por mim eu ficava grávida todo dia!'. Lucimar só queria tirar a licença maternidade quando entrasse em trabalho de parto. Como ela era uma "mulher saudável", ela havia optado pelo parto normal. Ela acrescenta: "meu bebê tá super bem, tá com um peso bom, isso eu acredito que pro reflexo do bebê é muito melhor, porque eu acho que... eu acho não, tenho certeza, no parto normal o neném nasce exatamente na hora que ele quer, ele não é forçado a sair a tirarem ele de lá, como acontece na cesárea". Por confiar no obstetra que a tratava e ter conhecimentos médicos ela própria, Lucimar não sentia nenhuma ansiedade em relação ao parto; "eu sei que tudo tá caminhando bem".

A história de Lucimar ilustra várias questões em torno da concepção, presentes em outras entrevistas. Primeiramente, a gravidez era algo desejado pelas mulheres e parte de um projeto de vida em família, sustentado pelo casal. Ainda que o marido de Lucimar preferisse esperar mais por razões financeiras, o desejo do filho não era questionado. Como Lucimar, que aos 33 anos havia se formado e já trabalhava como enfermeira, a maioria das gestantes já estava se consolidando em suas carreiras, de forma que viam como parte de suas biografias desejarem ter um filho naquele momento de vida. Muitas já tinham irmãos ou amigos com filhos, de modo que no seu círculo social a gravidez havia sido esperada e festejada.

Segundo, dado este desejo, engravidar foi um ato planejado, com a suspensão de métodos contraceptivos e a atenção a períodos de fertilidade. $\mathrm{Na}$ narrativa de Lucimar, as orações a Deus aliadas aos seus conhecimentos médicos produziram o resultado esperado, opinião compartilhada pelas outras mulheres evangélicas entrevistadas. Muitas achavam que, por usarem pílulas anticoncepcionais há anos, teriam dificuldade para engravidar, o que não se concretizou. Algumas mulheres tinham condições como endometriose ou ovários policísticos, mas com tratamento médico conseguiram ficar grávida com mais facilidade do que esperavam. Apenas uma das mulheres pesquisadas recorreu à fertilização in vitro. Curiosamente, o ato sexual não foi mencionado por nenhuma como elemento importante para a concepção; a participação masculina também não foi comentada. Engravidar aparecia assim como um ato que cabia às mulheres planejar, ideia que Lucimar afirmou 
textualmente, e, no caso de dificuldades, recorria-se à ciência/medicina ou à religião.

Outro ponto presente nesta e noutras narrativas é a reação do casal à confirmação da gravidez. Na história de Lucimar, seu marido reagiu com surpresa e custou a acreditar. A surpresa ou mesmo susto diante da constatação da gravidez foi expressa pela maioria das mulheres, apesar de a terem desejado e planejado. Recorrendo a testes de farmácia ou diretamente a exames de sangue, todas falaram do misto de felicidade e susto que sentiram, pois agora era pra valer. Com a notícia, vinham à mente questões práticas como o dinheiro para sustentar o filho, a organização da casa e do trabalho, além da preocupação com a saúde do feto e com o desenrolar da gravidez. O marido ou companheiro muitas vezes reagia até com mais intensidade e alegria à confirmação da gestação, tornando-se figura de apoio importante para suas mulheres.

Destaco aqui o significado do susto diante da notícia da gravidez, que contrasta com o fato dela ter sido esperada e resultado de ações planejadas. Como veremos abaixo, tanto as mudanças que surgem com a gravidez como as expectativas em torno da maternidade colocavam-se como terreno desconhecido que matizava a alegria e a felicidade com a conquista de algo desejado. Neste sentido, Lucimar foi uma exceção na sua afirmativa repetida de sentir-se feliz com a gravidez, por tê-la planejado e recebido como dádiva divina e por ter os conhecimentos médicos sobre a gestação, tema que trato a seguir.

\section{A gestação}

Julia começou dizendo que a gravidez não havia sido planejada. Ela tinha sido casada antes, sem filhos dessa união, e estava morando com os pais desde o divórcio. Começara a namorar Téo, que já tinha um filho, alguns meses antes. Julia tinha endometriose e já havia tentado engravidar várias vezes. Ela conta: "parei de tomar pílula assim, esperando que eu demorasse pelo menos uns 6, 7 meses para engravidar, que era o que todos os médicos diziam, né! Porque eu já tinha tentado bastante. E eu engravidei no $1^{\circ}$ mês. Então assim, eu queria muito, mas não foi exatamente planejado." Ficou feliz mas assustada com a notícia, que detonou uma série de mudanças práticas fazendo do início da gestação um período conturbado. Ela saiu da casa dos pais, retomou seu apartamento que estava alugado e passou a morar lá com Téo. Apesar de não se sentir mais enjoada como nos primeiros meses, Julia disse que ainda sofria um pouco com a adaptação na vida profissional. "Tem sido um pouco difícil pra mim... Ter que diminuir o volume de trabalho, ter que ser um pouco menos centralizadora, entendeu... Eu fiz uma viagem de trabalho há pouco tempo que me deixou muito baqueada fisicamente [...] fiquei muito cansada, tive uma gastrite violenta. [...]. Então assim, 
nesse segundo trimestre, que todo mundo diz que você fica muito disposta, eu tô sentindo um pouco alguns baques físicos sim. Eu to tomando muitas vitaminas, o que na verdade eu acho que faz um bem danado pro meu filho, mas eu acho que pro meu estômago, assim, deu uma pesada, sabe?" Julia dizia que não era uma pessoa que seguia todos os 'protocolos' do que se deve fazer na gravidez pois achava que mesmo se preparando, quando o neném nascesse, tudo mudaria. Ela havia parado de fumar nos primeiros três meses, mas 'sucumbira' depois, apesar de ter reduzido a quantidade de cigarros por dia. Apesar de se sentir mal e se ver criticada, ela também se justificou dizendo que mulheres de gerações anteriores, como sua mãe, fumaram durante a gestação. A experiência de sua mãe, que teve partos normais, também era uma referência para o seu desejo de ter um parto normal. Mas ao contrário dela que não quis tomar anestesia nos partos, Julia morria de medo de sentir dor e não queria nada 'alternativo', nem parto de '20 horas, sofrido'. E 'se a coisa começar a complicar, é cesariana na hora, assim... Não tem questão, sabe?"

Julia destacou-se das outras entrevistadas por ressaltar o quanto a gravidez havia perturbado sua rotina, principalmente seu trabalho. Embora feliz por já ter tentado engravidar antes sem sucesso, ela começou seu relato enfatizando que não havia sido propriamente planejada. Talvez por isso, as mudanças no seu cotidiano tenham sido mais sentidas, difíceis, nas suas palavras.

De uma maneira geral, a gravidez era vista como um período de grandes mudanças físicas e emocionais. A experiência física da gestação era muito variada entre as mulheres estudadas. Enquanto todos diziam que o segundo trimestre da gestação era melhor, Julia vinha enfrentando mais 'baques físicos' do que esperara, adoecendo mais facilmente. De fato, foi mais comum entre as entrevistadas ouvir relatos de problemas nos primeiros meses de gestação - sangramento ou ameaça de descolamento de placenta, tendo que ficar de repouso inicialmente, enjoo ou azia. Aquelas que já estavam no final da gravidez começavam a se sentir mais pesadas e mais cansadas. Independente da experiência, todas destacavam como não conseguiam mais seguir com seu ritmo de vida anterior, seja no trabalho, seja em casa, embora algumas achassem que estava sendo melhor do que esperavam.

Esta mudança no corpo, vista também como uma mudança de disposição, era quase sempre discutida como uma perda ou uma dificuldade com a qual tinham que conviver, como no caso de Julia que se ressentia de não conseguir trabalhar mais tanto quanto gostaria. Outras entrevistadas também comentaram não conseguir dar conta do trabalho do mesmo modo que antes. Algumas mulheres falaram também no receio de ficarem feias com gravidez, de 
embarangar, nas palavras de Daniela, pois as roupas que tinham não cabiam mais com a barriga e o ganho de peso. Só Patricia, que no passado havia lutado para não engordar, estava contente agora por poder mostrar a barriga com orgulho. Esta era uma barriga valorizada, ao contrário da 'barriga de gordura'.

A gravidez também era vista como uma experiência que trazia mais emotividade às mulheres. ${ }^{2}$ Muitas mulheres diziam que agora choravam com mais facilidade - ao ver filmes e programas de televisão, ou mesmo nas consultas médicas. Outras se sentiam mais irritadas de um modo geral - no trabalho, em casa, com tudo. Embora a irritação pudesse se transformar em estresse, sentimento a ser evitado e que discutirei mais abaixo, a emotividade maior que surgia com a gravidez era aceita com mais tranquilidade do que as mudanças corporais.

Em função destas transformações, a gravidez produzia, para elas, uma reorientação do comportamento cotidiano vista como necessária tanto para sua saúde, como para a do bebê. Julia, mesmo com dificuldades, estava deixando de ser centralizadora reduzira sua carga de trabalho, evitando as muitas viagens que antes fazia. Para muitas, o estresse, principalmente no trabalho, deveria ser reduzido, através de uma diminuição da carga de trabalho, pois era visto como fazendo mal ao bebê. Atividades que antes eram parte da rotina, como carregar peso, abaixar-se e, para muitas, fazer exercícios de força, tiveram que ser deixados de lado por serem considerados arriscados para a gestação. A visão de que agora deveriam se alimentar de forma mais equilibrada, evitando comer porcarias, era consenso e abraçada por muitas, embora nem sempre fosse fácil de seguir. Aqui a preocupação era tanto com o desenvolvimento saudável do bebê quanto com o ganho de peso extra a ser evitado por razões médicas (evitar hipertensão e diabetes) e estéticas. O consumo de bebida deveria ser reduzido e o fumo suspenso, fazendo de Julia uma exceção.

Junto com esta reorientação, a gravidez era vista como um período que demandava cuidados não só da gestante como também de vários especialistas. Apesar de repetirem a ideia de que gravidez não é doença, ninguém questionava o tratamento médico da gestação que prescrevia consultas médicas mensais e exames médicos de várias ordens. No grupo de gestante, surgiam alguns questionamentos em torno de certas recomendações médicas, estimulados pela coordenadora, mas o acompanhamento médico não era problematizado. Além disso, era comum a visão de que deviam complementar os cuidados médicos com atividades físicas dirigidas a gestantes, como hidroginástica ou ioga,

\footnotetext{
${ }^{2}$ Em outro artigo (Rezende, 2011b) discuto como esta associação entre gravidez e emotividade aparece em revistas para gestante.
} 
com intuito de aliviar desconfortos e preparar para um bom parto. Nem todas conseguiam realizá-las, mas mesmo entre estas havia a percepção de que o ideal era poder fazê-las. Todas buscavam se informar mais - através dos médicos, livros e sites sobre gravidez - como outra forma de cuidar da gestação.

A gravidez também era um período de preparação prática para as mudanças que viriam com o nascimento do bebê. Praticamente todas as gestantes estavam reformando suas casas, preparando um quarto só para o bebê. Algumas tinham viajado ou ainda iam para os Estados Unidos comprar parte do enxoval, carrinhos e outros acessórios para o bebê. Outras já estavam pesquisando creches ou entrevistando babás que as ajudariam com o bebê, pensando também no seu retorno ao trabalho após a licença maternidade.

Assim, a gravidez aparecia como uma etapa valorizada a ser cuidada pela gestante. As mudanças na rotina que estes cuidados exigiam eram feitas não apenas como forma de tratar de si, mas também ou mesmo principalmente para cuidar do bebê, já nomeado e tratado como pessoa com vontades e gostos. Com grande frequência, as entrevistadas referiam-se aos bebês como filhos, colocando-se assim como mães. Assim, Julia comentou que as vitaminas que ela tomava faziam um bem danado para o seu filho, mas havia the dado uma gastrite. O exemplo de Julia revelava uma concepção de maternidade, presente também nas outras entrevistadas, que implicava uma doação de si, ou mesmo sacrifício (Mayblin, 2011), para os bebês. Articulava-se aqui também uma visão de que criar filhos saudáveis seria um imperativo materno, sendo o cuidado com a saúde dos filhos tomado como uma forma de amor (Cadoná e Strey, 2014). O fato de a própria Julia ter retomado seu hábito de fumar mostra que este ideal de mãe, embora presente, não era fácil de ser desempenhado, tensão esta que também apareceu nas falas sobre o parto.

\section{O parto}

Daniela planejou engravidar e, após três meses tentando sem resultado, foi a um especialista em fertilização. Como tinha 35 anos e seu marido já tinha uma filha, foi para a consulta para 'poder começar a rastrear se tinha com algum problema' e, para sua surpresa, descobriu lá que estava grávida. No início, teve alguns enjoos e também um sangramento leve, mas agora não sentia mais nada. Entrando no quarto mês de gestação na época da pesquisa, Juliana dizia que "eu penso só em problema [...]. Mas eu acho que isso é natural, né, porque você fica querendo que o seu filho venha com saúde, você fica ansioso querendo saber se tem alguma coisa ou não". Seu pai e irmãos eram médicos e acompanhavam seus exames, de forma que se sentia mais informada que muitas mulheres. Daniela acabara de saber que esperava um menino e preparava a 
reforma do quarto que faria, sua viagem para os Estados Unidos para comprar o enxoval, etc. e reorganizava seu trabalho na firma de arquitetura, já pensando em sua licença maternidade. Ela conta: "Minha mãe é muito medrosa. E assim, isso eu acho que acabou passando pra mim, né? [...]. Eu fico pensando no parto, eu fico com medo... Mas tem que ter coragem!" Daniela queria fazer cesariana. "Parto normal nunca, nem pensar [...]. Só de pensar eu já tô passando mal [...]. Eu sou muito corajosa pra muita coisa, mas pra sentir dor, eu não sou ninguém. " Ainda não estava definido se a cesárea seria marcada ou se ela entraria em trabalho de parto. "Isso dai, realmente, eu te confesso que eu ainda não sei. Vou ver como é que vai ser a minha gravidez e tudo, né... Ainda tem tempo pra poder conversar com a médica, né. Eu acho que se eu me sentir bem, do jeito que eu tô me sentindo, eu vou esperar entrar em trabalho de parto. Senão, aí já agenda logo, porque eu não tô me sentindo bem e pronto".

Embora Daniela ainda estivesse no quarto mês de gestação, ela já tinha ideias definidas sobre o parto que gostaria de ter. Assim como ela, todas as gestantes estudadas falaram do parto, que surgia nas narrativas como um momento antecipado que tanto marcava o fim da gravidez como o início da presença do bebê fora do útero. Como disse acima, a gravidez já se constituía em uma etapa da maternidade na qual já se estabelecia uma relação de cuidado com o bebê antes de ele nascer. Se em outras épocas (Almeida 1987; Lo Bianco, 1985) a gravidez era um estágio para a maternidade e o parto, o rito de passagem que a instaurava, agora a maternidade começava antes e o parto ganhava outro sentido. Era algo a ser escolhido e planejado.

A atenção dada ao parto foi significativamente maior no grupo de gestantes do que nas entrevistas. Uma vez que um dos principais objetivos do grupo era preparar para o parto através de sessões de ioga e de troca de experiências, este era um dos principais temas, embora não o único, e aquele que produzia mais expressão de ansiedade e medo diante do trabalho do parto e da possibilidade de sentir dor (Rezende, 2012a). Já nas entrevistas, a forma como o parto aparecia era mais diversificada, bem como os sentimentos manifestados eram mais variados. Enquanto Julia e Daniela falaram do medo da dor do parto, Lucimar mostrara-se muito tranquila. Em alguns casos, o tema surgia espontaneamente; em outros, só em função de perguntas do nosso roteiro.

No grupo de gestante, havia uma nítida preferência pelo parto normal, cujas etapas haviam sido mais discutidas e estudadas. Era para ele que muitos dos exercícios de ioga eram dirigidos. Embora houvesse críticas a procedimentos médicos vistos como desnecessários e a insegurança sobre a 
adesão do obstetra ao parto normal, nem a coordenadora nem as gestantes criticavam a medicalização do parto, como aconteceu há trinta anos no grupo estudado por Salem (2007) e atualmente nos grupos favoráveis ao parto humanizado (Carneiro, 2012; Mendonça, 2013). Tampouco a cesárea em si era mal vista, sendo problematizada apenas quando feita sem necessidade.

Entre as mulheres entrevistadas prevalecia também o desejo de ter parto normal. Havia justificativas distintas para isso. Três mulheres eram enfermeiras e apresentaram seu conhecimento técnico para explicar que o parto normal seria melhor para a mulher e para o bebê, entendido como pessoa que decide quando quer nascer, como expressou Lucimar. As outras preferiam este parto por ter pessoas próximas - mãe, irmã, amigas - que haviam tido bons partos normais. Muitas vezes, surgia também a ênfase de que este era o parto mais natural, relacionado a uma natureza feminina, mesmo que houvesse anestesia e outras intervenções médicas. Associado a este aspecto estava a percepção, expressa principalmente no grupo de gestante, de que o parto normal consagrava a mulher como tal, em contraste com a cesárea que a faria menos mulher. Ainda assim, para elas, a cesárea não era descartada e seria justificada se houvesse alguma complicação no trabalho de parto, como disse Julia.

A preferência pela cesárea aparecia tanto entre algumas mulheres do grupo de gestante, como entre entrevistadas, como Daniela que ainda cogitava esperar entrar em trabalho de parto. Esta opção vinha sempre amparada na experiência traumática de parto normal de pessoas próximas ou então no fato de que estas também tinham elegido fazer cesáreas. Na visão de Daniela, ela tinha herdado o mesmo pavor da dor que sua mãe tinha e que a levou a fazer cesarianas. Daniela também apontou para outro aspecto da cesárea, destacado igualmente por outras mulheres: a possibilidade de ser agendada. Para Daniela, agendar ou não dependeria do seu bem-estar ao final da gravidez. Para Taís, outra entrevistada, o agendamento da cesárea era importante, pois seu marido trabalhava fora do Rio na época e queria estar presente no parto. É importante ressaltar que nenhuma das entrevistadas mencionou, em suas narrativas, a influência de seus obstetras nesta decisão, embora no grupo de gestantes a inclinação de muitos médicos à cesárea tenha sido discutida e problematizada.

Como parte do processo de escolha em torno do parto, a maioria já tinha decidido em que hospital elas teriam filho e quem elas gostariam que estivesse presente. Aspectos como a distância de casa, o tipo de berçário, além da reputação do hospital e da escolha do médico, contavam na seleção da maternidade. A participação do marido na hora do parto era vista como certa. Embora eles frequentassem pouco o grupo de gestante, por exemplo, várias 
decisões em torno do parto eram tomadas em conjunto com eles. Pais, irmãos, sogros e amigos também eram esperados na maternidade durante o processo.

O parto surgia, assim, como o momento final da gravidez, sendo também objeto de escolha - qual o tipo, em que hospital, na presença de quem. No processo de escolha, estava menos em questão as informações sobre cada tipo de parto e sim uma relação afetiva com eles, baseada fortemente na experiência das mães e também de outras pessoas próximas. A escolha do tipo de parto surgia referida aos desejos da mulher como sujeito - seja a cesárea para evitar a dor ou abreviar desconfortos, seja o parto normal para realizar uma experiência feminina por excelência, nem sempre associada à maternidade. Digo isso, pois quando se colocavam como mãe e pensavam na saúde do bebê como filho, aquelas que desejavam um parto normal aceitavam a possibilidade da cesárea se fosse preciso.

\section{Gravidez, parto e maternidade}

As histórias de Lucimar, Julia e Daniela são exemplos da variedade de narrativas sobre a experiência da gravidez entre as mulheres de camadas médias que estudei no Rio de Janeiro. Lucimar era evangélica e enfermeira e via sua gravidez como resultado de suas orações e seu planejamento resultando de seu conhecimento médico. Dizia-se feliz, tranquila e preparada para o parto, que desejava ser normal. Julia engravidou quando ainda não morava com seu namorado e oscilava entre achar que tinha planejado ou não a gestação. As mudanças com a gravidez a surpreenderam e afetaram seu ritmo de trabalho, o que era difícil de acostumar. Também preferia o parto normal, mas com toda assepsia hospitalar, e não hesitaria em ter cesárea se o parto se alongasse demais. Daniela planejou a gravidez, a redução da carga de trabalho, a viagem para os Estados Unidos, a reforma da casa e a contratação de uma babá para o nascimento do bebê, ainda que na época estivesse no quarto mês de gestação. Da mesma maneira, planejava uma cesárea, que poderia ser agendada, pois tinha pavor de sentir dor.

Em comum, Lucimar, Julia e Daniela pensavam a gravidez como um estágio inicial da maternidade, ao contrário de outras gerações (Almeida, 1987; Lo Bianco, 1985) e das israelenses estudadas por Ivry (2010) e das equatorianas pesquisadas por Morgan (1997), para as quais esta só começaria após o parto. Lucimar, Julia e Daniela, bem como as outras entrevistadas, não apenas se referiam ao bebê que esperavam como 'filhos', já com necessidades e desejos próprios, mas também viam a gestação como um período em que precisavam mudar suas rotinas para cuidar dele. Ainda que estas mudanças fossem custosas, a ideia de que como mãe deveriam se sacrificar em razão da 
saúde do filho surgia assim como orientação de conduta moral fundamental, parte de um valor mais amplo dado à maternidade (Mayblin, 2011; Carneiro, 2012). Visão esta presente também nas campanhas de amamentação discutidas por Cadoná e Strey (2014), nas quais a mãe figura como a responsável principal pela saúde dos filhos, sendo este cuidado entendido como forma de amor.

Ao mesmo tempo, a gravidez se colocava como narrativa que descrevia a transformação da mulher em mãe. A temporalidade da narrativa conformava assim a biografia das mulheres, ao fazer o sujeito da história passar por mudanças gradativas, terminando em um estado distinto do inicial. Era uma transformação desejada e vista por todas como adequada ao momento biográfico em que estavam - casadas ou em relações amorosas estáveis, com situação profissional estabelecida e a maioria com casa própria. $\mathrm{Na}$ maioria das narrativas, a mulher enquanto sujeito apresentava-se como agente, que pensava suas escolhas, mantinha controle relativo de seus corpos e planejava as ações adequadas, desde a concepção ao parto. Ainda que outros sujeitos estivessem presentes e interferissem no transcorrer da gestação, mantinha-se a ênfase maior na agência das mulheres, questão apontada também por outros autores (Lupton e Schmied, 2013; Thomson et al., 2011).

Aqui, quero ressaltar o que sobressai nas narrativas destas mulheres, mesmo que em seus cotidianos a família e os médicos afetassem o desenvolvimento de suas gestações e limitassem seu poder de agência. Não questiono as relações de poder presentes entre os médicos e as mulheres, que assume formas variadas a começar pelo próprio discurso de verdade sobre o corpo que os primeiros enunciam na posição de autoridades (Foucault, 1977; Rabinow e Rose, 2006). Em outro trabalho (Rezende, 2012b), discuto as relações tensas com os obstetras, pautadas pelas restrições impostas pelo plano de saúde em termos tanto da escolha do médico como também do hospital para ter o parto. Mas, na perspectiva das narrativas da gravidez de forma mais ampla, o que se destacava era o planejamento e o controle de si.

O único sujeito que era apresentado como modulando de fato esta agência era o filho bebê. Era por conta dele que as mulheres passavam por desconfortos físicos, mudanças emotivas, alterações na rotina de trabalho, na alimentação, hábitos de exercício e de cuidados estéticos. Era em função dele que todas iniciavam processos de rearrumação do espaço físico de suas casas. Era em nome deles também que abririam mão do parto desejado.

No entanto, na medida em que esta atribuição de agência ao bebê filho era com frequência uma limitação do poder de ação das mulheres, produziam-se sentimentos ambivalentes ao longo das narrativas. A concepção era recebida com alegria e também susto. As mudanças com a gestação eram referidas ao bom 
desenvolvimento do bebê desejado, mas também significavam desconfortos físicos e perdas. O parto era foco de planejamento detalhado e ao mesmo tempo temido e imprevisível. Esta ambivalência sugeria assim as dificuldades, para mulheres que buscavam planejar muito do que acontecia em suas vidas, de deixar de ter tal controle de si, mesmo quando fosse por um filho desejado. Mostrava também como o ideal de mãe que se sacrifica pelo filho, ainda que reconhecido como moralmente válido por todas, era difícil de ser abraçado na prática.

É, portanto, neste contexto de significados culturais de maternidade e feminilidade bem como de noções de pessoa - a mulher como agente, o bebê como sujeito - que a gravidez e o parto devem ser entendidos, referidos a indivíduos com situações sociais particulares - mulheres com mais de trinta anos, casadas, trabalhando em ocupações de camadas médias, com religiões que produzem visões de mundo específicas. A dimensão de geração é importante aqui, pois estas mulheres já tomam como dado valores individualistas que gerações anteriores tiverem que afirmar (Barros et al., 2009), bem como a mudança nos papéis de gênero que passou a conferir significado à realização tanto pelo trabalho quanto pela maternidade (Araújo e Scalon, 2005; Scavone, 2001).

Ainda que neste conjunto de entrevistadas eu não tenha encontrado discursos defensores do parto humanizado, com ênfases explícitas no protagonismo da mulher, o parto aparecia como objeto de escolha e planejamento, em sintonia com tudo o mais na gravidez. Embora a estetização da qual fala Tornquist (2002) remetesse ao parto humanizado principalmente, vejo aqui também uma estética do parto, a ser vivenciado de acordo com um planejamento de todos os seus detalhes. Fazia sentido assim para um conjunto de mulheres que se viam como agentes responsáveis por organizar seus corpos e suas vidas para terem um filho. Na medida em que a gravidez já era a etapa inicial da maternidade, o parto não era mais um rito de passagem que transformava a mulher em mãe, mas sim um marco na relação da mãe com seu filho, agora fora da barriga e ainda menos sujeito ao seu controle. Sugiro, portanto, que ter um parto tal como desejado, normal ou cesárea, coroava e encerrava apropriadamente uma gestação que havia sido cuidadosamente planejada desde o início, articulando noções de feminilidade a concepções de maternidade.

\section{Referências}

ALMEIDA, Maria Isabel Mendes de. Maternidade, um destino inevitável? Rio de Janeiro: Campus, 1987.

ARAÚJO, Clara; SCALON, Celi. Percepções e atitudes de mulheres e homens sobre a conciliação entre família e trabalho pago no Brasil. In: Clara Araújo; Celi Scalon (Orgs.). Gênero, familia e trabalho no Brasil. Rio de Janeiro: FGV, 2005. p. 15-77. 
ARFUCH, Leonor. O espaço biográfico: dilemas da subjetividade contemporânea. Rio de Janeiro: Uerj, 2010.

BARROS, Myriam Lins de; CORREA, Ana Carolina Ferraz; ARNALDO, Camila Cunha; STEFFENON, R. Mulheres, geração e trabalho. Interseções: Revista de Estudos Interdisciplinares, v. 11, n. 2, p. 335-351, 2009.

CADONÁ, Eliane; STREY, Marlene Neves. A produção da maternidade nos discursos de incentivo à amamentação. Revista Estudos Feministas, v. 22, n. 2, p. 477-499, 2014. $<$ dx.doi.org/10.1590/S0104-026X2014000200005> (29 set. 2014).

CARNEIRO, Rosamaria Giatti. E parto natural é arriscado, é? Notas etnográficas de experiências femininas de parto humanizado. Revista Coletiva, v. 9, p. 1-5, 2012 $<$ Www.coletiva.org/site/index> (28 set. 2014).

DAVIS-FLOYD, Robbie E. The rituals of American hospital birth. In: David McCurdy (Org.). Conformity and conflict: readings in cultural anthropology. 8. ed. New York: Harper Collins, p. 323-340, 1994.

DINIZ, Simone. Humanização da assistência ao parto no Brasil: os muitos sentidos de um movimento. Ciência \& Saúde Coletiva, v. 10, n. 3, p. 627-637, $2005<\mathrm{dx}$.doi. org/10.1590/S1413-81232005000300019>.

FOUCAULT, Michel. Vigiar e Punir. Petrópolis: Vozes, 1977.

HIRSCH, Olivia Nogueira. "O parto humanizado": um estudo comparativo sobre gravidez, corpo e identidades. Rio de Janeiro, 2011. Texto de qualificação para o doutorado, Programa de Pós-Graduação em Ciências Sociais, PUC-Rio.

IVRY, Tsipy. Embodying culture: pregnancy in Japan and Israel. London: New Brunswick, 2010.

LO BIANCO, Anna Carolina. A psicologização do feto. In: Sérvulo Figueira (Org.). Cultura da psicanálise. São Paulo: Brasiliense, 1985. p. 94-115.

LUPTON, Deborah; SCHMIED, Virginia. Splitting bodies/selves: women's concepts of embodiment at the moment of birth. Sociology of Health \& Illness, v. 35, n. 6, p. 828-841, $2013<$ dx.doi.org/10.1111/j.1467-9566.2012.01532.x> (29 set. 2014).

MAYBLIN, Maya. The madness of mothers: agape, love and the maternal myth in Northeast Brazil. American Anthropologist, v. 114, n. 2, p. 240-252, 2011.

MENDONÇA, Sara Sousa. Mudando a forma de nascer: agência e construções de verdades entre ativistas pela humanização do parto. Rio de Janeiro, 2013. Dissertação de mestrado em Antropologia, Universidade Federal Fluminense.

MORGAN, Lynn. Imagining the unborn in the Ecuadorean Andes. Feminist Studies, v. 23, n. 2, p. 323-350, 1997.

RABINOW, Paul; ROSE, Nikolas. O conceito de biopoder hoje. Revista de Ciências Sociais: Politica \& Trabalho, n. 24, p. 27-57, 2006.

RAGONÉ, Helena. Chasing the blood tie: surrogate mothers, adoptive mothers and fathers. In: Louise Lamphere; Helena Ragoné; Patricia Zavella (Orgs.). Situated lives: gender and culture in everyday life. Londres: Routledge, 1997. p. 110-127.

REZENDE, Claudia Barcellos. The experience of pregnancy: subjectivity and social relations. Vibrant, v. 8, p. 529-549, 2011a. 
REZENDE, Claudia Barcellos. Um estado emotivo: representação da gravidez na mídia. Cadernos Pagu, v. 36, p. 315-344, 2011 b.

REZENDE, Claudia Barcellos. Em torno da ansiedade: subjetividade, mudança e gravidez. Interseções: Revista de Estudos Interdisciplinares, v. 14, p. 438-454, $2012 \mathrm{a}$.

REZENDE, Claudia Barcellos. Trust between pregnant women and their obstetricians. Viena, 2012b. Trabalho apresentado no 54. International Congress of Americanists.

SALEM, Tania. O casal grávido: disposições e dilemas da parceria igualitária. Rio de Janeiro: FGV, 2007.

SCAVONE, Lucila. Maternidade: transformações na família e nas relações de gênero. Interseções: Revista de Estudos Interdisciplinares, v. 5, n. 8, p. 47-60, 2001.

THOMPSON, Charis. Strategic naturalizing: kinship in an infertility clinic. In: Sarah Franklin; Susan McKinnon (Orgs.). Relative values: reconfiguring kinship studies. Durham: Duke University Press, 2001. p. 175-202.

THOMSON, Rachel; KEHILY, Mary Jane; HADFIELD, Lucy; SHARPE, Sue. Making modern mothers. Bristol: Policy Press, 2011.

TORNQUIST, Carmem Susana. Armadilhas da nova era: natureza e maternidade no ideário da humanização do parto. Revista Estudos Feministas, v. 10, n. 2, p. 483-492, $2002<$ dx.doi.org/10.1590/S0104-026X2002000200016>.

Recebido em: 18 out. 2014

Aprovado em: 12 jan. 2015

Autora correspondente:

Claudia Barcellos Rezende

Instituto de Ciências Sociais

Rua São Francisco Xavier, 524 sala 9019 bloco B - Maracanã

20550-900 - Rio de Janeiro, RJ 